\title{
Prevalence of Risk Factors for Uterine Fibroids at Tertiary Care Teaching Hospital: A Cross-sectional Study
}

\author{
Navaneetha Krishnan Subramaniyam ${ }^{1 *}$, Vanaja Kandluri ${ }^{2}$, Ajay Chadeve', Dijitha Modapu', Aruna jyothi Dumpala', Bhargava Reddy \\ Gudise', Narahari Narayan Palei ${ }^{3}$, B. Jeevan Kumar' ${ }^{1}$, Battula Pradeep ${ }^{1}$ \\ 'Department of Pharmacy Practice, Sree Vidyanikethan College of Pharmacy, Tirupati, Andhra Pradesh, INDIA. \\ 2Department of Obstetrics and Gynecology, Sri Venkateswara Institute of Medical Sciences, Tirupati, Andhra Pradesh, INDIA. \\ ${ }^{3}$ Department of Pharmaceutics, Sree Vidyanikethan College of Pharmacy, Tirupati, Andhra Pradesh, INDIA.
}

\begin{abstract}
Objectives: To examine the prevalence of risk factors in patients suffering from uterine fibroid at tertiary care teaching hospital. Methods: A crosssectional study carried out between June to December 2019 includes patients who were diagnosed with uterine fibroids in the gynecology department, SVIMS, Tirupati. The position and number of the fibroids were counted and noted by the reports of Ultrasound examinations. Especially we assessed the prevalence of risk factors for uterine fibroids based on the questionnaire filled by the patients. The data were processed with the statistical program SPSS 25 and P value less than 0.05 were considered to be statically significant. Results: A total of 137 patients was studied, the majority of subjects were below the age group of $36-50$ years $(63.5 \%)$ followed by $21-35$ years $(24.08 \%)$ and $51-65$ years $(12.4 \%)$. The average age of the participants was $42.08 \pm 8.89$ years. BMl showed that women with $25 \mathrm{~kg} / \mathrm{m}^{2}$ to $29.9 \mathrm{~kg} / \mathrm{m}^{2}(54.74 \%)$ and $\geq 30 \mathrm{~kg} / \mathrm{m}^{2}(8.75 \%)$ experienced a higher prevalence of fibroids $\left(\chi^{2}=11.55, P=0.003\right)$ than women with $18.5 \mathrm{~kg} / \mathrm{m}^{2}$ to $24.9 \mathrm{~kg} / \mathrm{m}^{2}$ (36.49\%). The average body mass index (BMI) of
\end{abstract}

women with fibroids that were detected in our study was $27.5 \mathrm{~kg} / \mathrm{m}^{2}$. Other risk factors were not significantly linked with uterine fibroids. Conclusion: Fibroid prevalence had a significant correlation with age and BMI. Early detection and reduced body weight may bring down the occurrence of uterine fibroids.

Key words: Uterine fibroids, Cross-sectional study, Risk factors, Obesity, Body Mass Index (BMI).

Correspondence

Dr. S. Navaneetha Krishnan

Department of Pharmacy Practice, Sree Vidyanikethan College of Pharmacy, Tirupati- 517102, Andrapradesh, INDIA.

Phone: +919952627886

Email: nasveen@gmail.com

DOI: 10.5530/jyp.2020.12.17

\section{INTRODUCTION}

Uterine fibroids (UFs), also known as uterine leiomyomas, are benign smooth muscle tumors of the uterus that affect women of reproductive age. ${ }^{1-3}$ They may be asymptomatic or cause a range of severe and chronic symptoms. The most common presenting symptom is heavy menstrual bleeding, which can lead to anemia and fatigue and painful periods. ${ }^{4-9}$ The growth of leiomyoma is dependent on estrogen production. UFs are more common in overweight women because of increased estrogen from adipose aromatase activity. ${ }^{10}$

Many different risk factors have been associated with the development of UFs, including biological, demographic, reproductive and lifestyle factors such as age, obesity, overweight, caffeine consumption, early age at menarche, vitamin D deficiency, black race, family history, hypertension, diabetes, use of soya bean milk, polycystic ovarian syndrome and red meat consumption. ${ }^{11,12}$ Management of UFs mainly depends on the symptoms, location and size of the fibroid. UFs are one of the contributing causes of hospitalizations for gynecological disorders are the most frequent reason for the hysterectomy. There is little known about risk factors for uterine fibroids, therefore, this study aimed to examine the prevalence of risk factors for uterine fibroid in the outpatient department (OPD) and inpatient department, Sri Venkateswara Institute of Medical Sciences (SVIMS), Tirupati, Andhra Pradesh, India.

\section{MATERIALS AND METHODS}

\section{Study design and Ethical consideration}

A cross-sectional study on the prevalence of risk factors for uterine fibroids was conducted in a tertiary care teaching hospital Sri Venkateswara
Institute of Medical Sciences, Tirupati, Andhra Pradesh, India in 2019. The ethical clearance was obtained from the Institutional Ethics Committee with approved IEC NO. 918 from Sri Venkateswara Institute of Medical Sciences and the consent was taken from subjects. The study was performedper ICH GCP Guidelines.

\section{Selection criteria}

Patients between 21-65 years, patients diagnosed with uterine fibroids, and patients willing to participate were taken inclusion criteria. The pregnant women were omitted from the study.

\section{Sample size}

One hundred and thirty-seven patients diagnosed with uterine fibroids were taken as sample size and examined as per study guidelines.

\section{Method of Collection of Data}

The informed consent form was obtained from all subjects prior the study. On the day of the examination, all participants were allowed to sign in the Informed Consent Form. In addition to basic information regarding the age, altitude, weight and education, we assessed the location, size and number of fibroids with the help of Ultrasonography reports [USG]. The questionnaire also asked about smoking, caffeine consumption, parity, participant's health status (hypertension, diabetes mellitus) and close to the family history of the disease (fibroids) in the patient. 


\section{Statistical analysis}

The data was collected and recorded in a pre-designed proforma and managed using Microsoft Excel worksheet (Microsoft Corp, Redmond, WA) and SPSS version 25 (Statistical Package for Social Sciences) during the final analysis. Socio-demographic details, location and several nodules were represented in percentage. The relationship between descriptive variables was analyzed with the Pearson chi-square test by testing equality between the observed and expected frequencies. The limit of statistical significance was at $p<0.05$.

\section{RESULTS}

A Total number of 290 uterine fibroid patients were approached to contribute to this field, but only 137 uterine fibroid patients were responding to our study and participated in the study, Before that we have clearly explained about the study to the subjects. All the subjects involved in this study were voluntarily accepted to participate.

\section{Data evaluation based on location and number of fibroids}

The results of the fibroids characteristics such as positioning and number are presented in Figures 1 and 2. Fibroid incidence showed a statistically significant correlation with Age. The majority of subjects were under the age group of $36-50$ years $(n=87)$ constituting $63.5 \%$ of patients observed by age group of $21-35$ years $(n=33)$ constituting $24.08 \%$ of patients followed with the age group of $51-65$ years $(n=17)$ constituting $12.4 \%$ of patients as shown in Table 1.

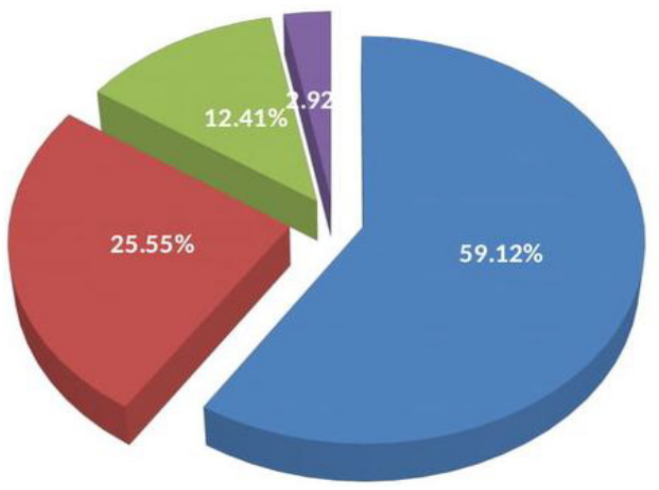

Intramural

- Subserosal

Submucosal

- Pedunculated

Figure 1: Distribution of Uterine fibroids patients based on the location of fibroids.

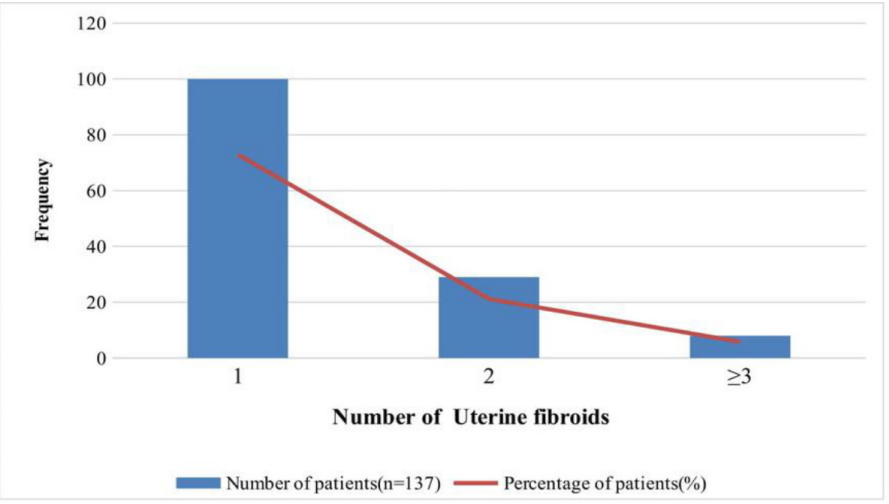

Figure 2: Distribution of Uterine fibroids patients based on number of fibroids.
Data evaluation based on social-demographic details of the patient

Out of 137 study populations, the average age of the participants was $42.08 \pm 8.89$ years and $95.6 \%$ were married and the rest were unmarried and widowed, $64.9 \%$ of patients were illiterate and $35.05 \%$ were literate. The rural patients are $71.5 \%$ and $28.05 \%$ were from the urban part and out of all $91.9 \%$ of the patients belong to the Hindu faith and the rest of all belongs to Muslim and Christian, which were shown in Table 2.

\section{Analysis of the main significant risk factor associated with the prevalence of fibroids}

The average body mass index (BMI) of women with fibroids that were detected in our study was $27.5 \mathrm{~kg} / \mathrm{m}^{2}$. Based on the BMI score women were divided into 3 categories; Normal $\left(18.5 \mathrm{~kg} / \mathrm{m}^{2}\right.$ to $\left.24.9 \mathrm{~kg} / \mathrm{m}^{2}\right)$, Overweight $\left(25 \mathrm{~kg} / \mathrm{m}^{2}\right.$ to $\left.29.9 \mathrm{~kg} / \mathrm{m}^{2}\right)$ and obese $\left(\geq 30 \mathrm{~kg} / \mathrm{m}^{2}\right)$. The comparison of individual categories of BMI, the results showed that women with overweight(54.74\%) had a higher prevalence of fibroids $\left(\chi^{2}=11.55, P=0.003\right)$ than women with normal BMI (36.49\%). BMI distribution was shown in Figure 3.

\section{Non-significant risk factors associated with the prevalence of fibroids}

In our study, we also found the importance of the other risk factors which might throw a possible role in the occurrence of fibroids. Three major groups of risk factors were analyzed: gynecological history (age at menarche, family history of fibroid), Lifestyle (caffeine ingestion) and Medical history (hypertension, diabetes mellitus) were not statistically significantly associated with fibroids. These results are shown in Table 3.

Table 1: Age distribution among all uterine fibroids patients.

\begin{tabular}{|c|c|c|c|}
\hline S.NO & Age Group (Years) & $\begin{array}{c}\text { Number of Patients } \\
(\boldsymbol{n}=\mathbf{1 3 7 )}\end{array}$ & $\begin{array}{c}\text { Percentage } \\
(\%)\end{array}$ \\
\hline 1 & $21-35$ & 33 & 24.08 \\
\hline 2 & $36-50$ & 87 & 63.50 \\
\hline 3 & $51-65$ & 17 & 12.40 \\
\hline
\end{tabular}

Table 2: Socio-demographic data of the uterine fibroid patients in the department of OBG.

\begin{tabular}{|c|c|c|c|}
\hline \multirow{4}{*}{ Marital Status } & Category & $\begin{array}{c}\text { Number of Patients } \\
(\boldsymbol{n}=\mathbf{1 3 7 )}\end{array}$ & $\begin{array}{c}\text { Percentage } \\
(\%)\end{array}$ \\
\cline { 2 - 4 } & Married & 131 & 95.6 \\
\hline & Unmarried & 1 & 0.72 \\
\hline \multirow{4}{*}{ Education } & Widow & 5 & 3.64 \\
\hline \multirow{3}{*}{ Religion } & Literate & 48 & 35.05 \\
\cline { 2 - 4 } & Illiterate & 89 & 64.9 \\
\cline { 2 - 4 } & Hindu & 126 & 91.9 \\
\cline { 2 - 4 } & Muslim & 10 & 7.29 \\
\hline \multirow{5}{*}{ Residency } & Christian & 1 & 0.72 \\
\cline { 2 - 4 } & Urban & 39 & 28.5 \\
\hline \multirow{2}{*}{ Parity } & Rural & 98 & 71.5 \\
\cline { 2 - 4 } & Nulliparous & 14 & 10.2 \\
\cline { 2 - 4 } & 1 & 16 & 11.6 \\
\cline { 2 - 4 } & 2 & 78 & 56.9 \\
\cline { 2 - 4 } & $\geq 3$ & 29 & 21.1 \\
\hline
\end{tabular}




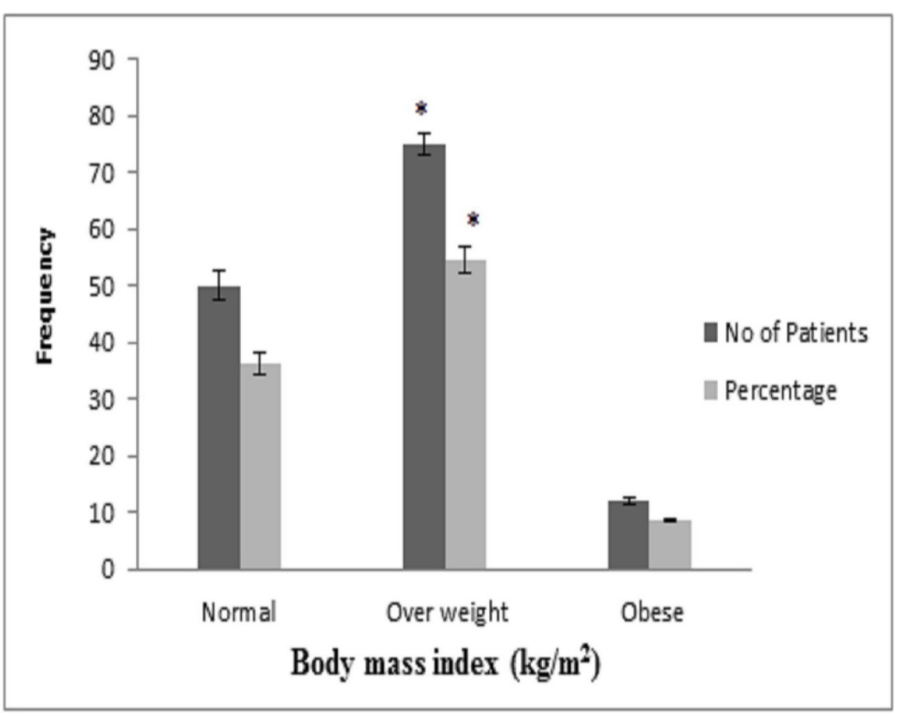

Figure 3: The uterine fibroid patients Body Mass Index, a significant risk factor associated with the prevalence of fibroids.

Table 3: The non-significant effects of risk factors associated with uterine fibroids patients.

\begin{tabular}{|c|c|}
\hline Risk Factors & Statistical Significance \\
\hline Caffeine consumption & $\chi^{2}=1.83, \mathrm{p}=0.400$ \\
\hline Family history & $\chi^{2}=2.30, \mathrm{p}=0.317$ \\
\hline Hypertension & $\chi^{2}=0.16, \mathrm{p}=0.922$ \\
\hline Diabetes mellitus & $\chi^{2}=1.69, \mathrm{p}=0.428$ \\
\hline Early age at menarche & $\chi^{2}=0.36, \mathrm{p}=0.833$ \\
\hline
\end{tabular}

$p<0.05$ statistically significant

\section{DISCUSSION}

Uterinemyomas or fibromyomas are rising from the myometrium smooth muscle and it's a slow growing benign (non-cancerous) tumor. The fibroids developinggradually into the massive size and make menorrhea condition. ${ }^{13}$ One-third of Gynaecology admissions are leiomyomas with menstrual disturbance, anemia and lump with abdomen colic. ${ }^{14}$ Fibroids gradually get escalation in size as women get older and it's a basis pressure warning sign leads to the majority required surgical interventions resembling myomectomy or hysterectomy. ${ }^{15}$ The present study aimed to assess the prevalence of risk factors for uterine fibroids among women aged between 21-65 years.

The socio-demographic data summarized that married women predominantly affected with fibroids. The present study findings were consonances with an earlier study that there was no association between the incidence of fibroids and the matrimonial status of the patient. ${ }^{16}$ More Hindu religion people (91\%) came to the hospital and diagnosed with uterine fibroids compared to the other religious people, it might be due to more hindu population in study area. In our study, more than $80 \%$ of the patients from rural areas were found fibroids than urban areas due to a lack of health care centers. More than half of this study sample population $(64.9 \%)$ were illiterate and had no knowledge of reproductive health and hygiene which can potentially delay the women seeking treatment at the initial stages of reproductive health problems.

Age is a significant and clear predictor for uterine fibroid in women. In our present study, we found an increase in the occurrence of the fibroid in the age group of 35-50 years. These detections were under the previous study reports that the presence of this uterine fibroid condition was more frequently seen in the $40-44$ years, age groups. ${ }^{17}$

It was perceived that Uterinemyomas are most common ( BMI $>30 \mathrm{~kg} / \mathrm{m}^{2}$ ) in obese women. Body weight of $70 \mathrm{~kg}$ or more denotes a nearly threefold augmented risk of incidence of fibroids compared with a body weight of $50 \mathrm{~kg} \cdot{ }^{18}$ Raised BMI has a more influence on the risk of the incidence of fibroids after the age of 18 , if it is higher than $20 \mathrm{~kg} / \mathrm{m}^{2}$. Its supreme effect has been seen between $27.5 \mathrm{~kg} / \mathrm{m}^{2}$ and $29.9 \mathrm{~kg} / \mathrm{m}^{2} .^{19}$ In the present study outcomes of BMI revealed that women with $25 \mathrm{~kg} / \mathrm{m}^{2}$ to $29.9 \mathrm{~kg} / \mathrm{m}^{2}(54.74 \%)$ and $\geq 30 \mathrm{~kg} / \mathrm{m}^{2}(8.75 \%)$ experienced a higher prevalence of fibroids $\left(\chi^{2}=11.55, P=0.003\right)$ than women with $18.5 \mathrm{~kg} / \mathrm{m}^{2}$ to $24.9 \mathrm{~kg} / \mathrm{m}^{2}(36.49 \%)$. Parallel results were noticed in another study that, the higher BMI shows a significant association with uterine fibroids $\left(\chi^{2}=9.6, p=0.002\right){ }^{20}$

Intramural fibroid appears to decline fertility than other types of fibroid which indicate the strong connection between different type of fibroids and reproductive consequence. ${ }^{21}$ In the present study, more intramural fibroids are prominent (59.12\%) which has a positive association to cause spontaneous abortion.

We assessed the importance of the other risk factors which might throw a possible role in the occurrence of fibroids. Three major groups of risk factors were analyzed such as gynecological history, lifestyle and medical history. Although early age at menarche showed to be important in association with fibroids development however our study did not reveal any significance. ${ }^{22,23}$ Moreover, we did not get any significant correlation between any of the lifestyle habits, like caffeine consumption and the occurrence of fibroids, even though some authors describe these features as significant. ${ }^{24,25}$ The family history is one of the main predisposing factors for uterine leiomyoma, ${ }^{26}$ but in our study family history have not shown any significant association with uterine fibroids. Some reports in the literature showed fibroids to be more frequent in women who experience arterial hypertension and diabetes, ${ }^{27}$ However, our results do not confirm this association. There is a negative association between parity and the risk of fibroids in our subject area which is consistent with the findings in previous studies. ${ }^{28,29}$

\section{CONCLUSION}

Uterine fibroids can cause multiple bleeding and painful symptoms which might harm women's life, influencing their sexual, social and work life. The prevalence of risk factors for uterine fibroids in our area were found to be significantly associated with higher BMI and age between 35-50 years. We found that gynecological history, lifestyle and medical history of the patients were not significantly associated with uterine fibroids.Early detection and health awareness camps in rural areas would help in early management and thereby reduce the morbidity.

\section{ACKNOWLEDGEMENT}

We acknowledge entire health care Authorities for their appropriate response, along with the volunteers who big heartedly provided support at the SVIMS hospital, Tirupati. The authors are grateful to Dr.Uma Maheswara Rao, Pharm. D Coordinator, SVIMS, Tirupati, Andhra Pradesh, India, for his continuous direction and care for this study.

\section{CONFLICT OF INTEREST}

Authors declare no conflicts of interest.

\section{REFERENCES}

1. Kempson RL, Hendrickson MR. Smooth muscle, endometrial stromal and mixed Mullerian tumors of the uterus. Mod Pathol. 2000;13(1):328-42. 
2. Cramer SF, Patel A. The frequency of uterine leiomyomas. Am J Clin Pathol. 1990;94(4):435-8.

3. Fields KR, Neinstein LS. Uterine myomas in adolescents: Case reports and a review of the literature. J Pediatr Adolesc Gynecol. 1996;9(4):195-8.

4. Stewart EA. Uterine fibroids. Lancet. 2001;357(9252):293-8.

5. JrButtram VC, Reiter RC. Uterine leiomyomata: Etiology, symptomatology and management. Fertil Steril. 1981;36(4):433-45.

6. Khan AT, Shehmar M, Gupta JK. Uterine fibroids: Current perspectives. Int $J$ Womens Health. 2014;6(7):95-114.

7. Kjerulff KH, Langenberg P, Seidman JD, Stolley PD, Guzinski GM. Uterine leiomyomas. Racial differences in severity, symptoms and age at diagnosis. J Reprod Med. 1996;41(7):483-90.

8. Carlson KJ, Miller BA, JrFowler FJ. The Maine Women's Health Study: II. Outcomes of nonsurgical management of leiomyomas, abnormal bleeding and chronic pelvic pain. Obstet Gynecol. 1994;83(4):566-72.

9. Zimmermann A, Bernuit D, Gerlinger C, Schaefers M, Geert K. Prevalence, symptoms and management of uterine fibroids: An international internet-based survey of 21,746 women. BMC Womens Health. 2012;26(3):12-6.

10. MSD MANUAL Professional Version. 2019. https://www.msdmanuals.com/ en-kr/professional/gynecology-and-obstetrics/uterine-fibroids/uterine-fibroids

11. Stewart EA, Cookson CL, Gandolfo RA, et al. Epidemiology of uterine fibroids: A systematic review. BJOG: An International Journal of Obstetrics and Gynaecology. 2017;124(10):1501-12.

12. Pavone D, Clemenza S, Sorbi $F$, et al. Epidemiology and risk factors of uterine fibroids. Best Pract Res Clin Obstet Gynaecol. 2018;46(1):3-11.

13. Ibrar F, Raiza S, Dawood NS, Jabeen A. Frequency of fibroid uterus in multipara women in a tertiary care centre in Rawalpindi. J Ayub Med Coll Abbottabad. 2010;22(3):155-7.

14. Garg R. Two uncommon presentation of cervical fibroids. People's J Sci Res. 2012;5(2):36-8

15. Gloria A, Bachmann MD, Linda A, Bahouth BA, Amalraj P, Mhamunkar V. Correlation of anemia and pain to fibroid location and uterine weight. J Reprod Med. 2011;56(11-12):463-6.
16. Olatinwo AW, Ofiong R. An Analysis of Surgically Treated Cases of Uterine Fibroids at the University of Ilorin Teaching Hospital, Ilorin, Nigeria. Nigerian $\mathrm{J}$ Surg Res. 2000;2(1):6-11.

17. Chen CR, Buck GM, Courey NG, Perez KM, Wactawski-Wende J. Risk factors for uterine fibroids among women undergoing tubal sterilization. Am J Epidemiol. 2001;153(1):20-6.

18. Flake GP, Andersen J, Dixon D. Etiology and pathogenesis of uterine leiomyomas: A review. Environ Health Perspect. 2003;111(8):1037-54.

19. Lobel MK, Somasundaram P, Morton CC. The genetic heterogenity of uterine leiomyomata. Obstet Gynecol Clin North Am. 2006;33(1):13-39.

20. Marshall LM, Spiegelman D, Manson JE, et al. Risk of uterine leiomyomata among premenopausal women in relation to body size and cigarette smoking. Epidemiology.1998;9(5):511-7.

21. Pritts EA, Parker WH, Olive DL. Fibroids and infertility: An updated systematic review of the evidence. Fertil Steril. 2009;91(3):1215-23.

22. Vitiello D, McCarthy S. Diagnostic imaging of myomas. Obstet Gynecol Clin North Am. 2006;33(1):85-95.

23. Gupta S, Manyonda IT. Acute complications of fibroids. Best Pract Res Clin Obstet Gynaecol. 2009;23(5):609-17.

24. Wise LA, Palmer JR, Stewart EA, et al. Age-specific incidence rates for self-reported uterine leiomyomata in the Black Women's Health Study. Obstet Gynecol. 2005;105(3):563-8.

25. Parazzini F, Negri E, LaVecchia $C$, et al. Uterine myomas and smoking: Results from an Italian study. J Reprod Med. 1996;41(5):316-20.

26. Okolo S. Incidence, aetiology and epidemiology of uterine fibroids. Best Pract Res Clin Obstet Gynaecol. 2008;22(4):571-88.

27. Ross RK, Pike MC, Vessey MP, Bull D, Yeates D, Casagrande JT. Risk factors for uterine fibroids: Reduced risk associated with oral contraceptives. $\mathrm{Br}$ Med J. 1986;293(6543):359-62.

28. Parazzini F, Negri E, LaVecchia C, et al. Reproductive factors and risk of uterine fibroids. Epidemiology. 1996;7(4):440-2

29. Cramer SF, Horiszny JA, Leert P. Epidemiology of uterine leiomyomas with an etiologic hypothesis. J Reprod Med. 1995;40(8):595-600.

Article History: Submission Date :05-02-2020 ; Revised Date : 22-02-2020 ;Acceptance Date : 29-02-2020

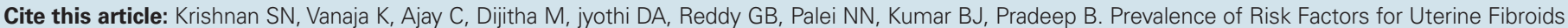
at Tertiary Care Teaching Hospital: A Cross-sectional Study. J Young Pharm. 2020;12(1):86-9. 